\title{
Metastatic cerebellar abscess producing nerve deafness
}

\author{
CHRISTOPHER GARDNER-THORPE AND S. T. AL-MUFT I \\ From the Wessex Neurological Centre, General Hospital, Southampton
}

Posterior fossa abscesses are uncommon spaceoccupying lesions and are rarely metastatic in origin. No case has been found in the literature of nerve deafness due to a cerebellar space-occupying lesion.

\section{CASE REPORT}

A television technician aged 48 was admitted to the Wessex Neurological Centre (Case no. 7529) on 28 January 1969. About three weeks before this he had noticed deafness in the left ear and had felt ill and nauseated. The next day he had an attack of throbbing left-sided headache lasting 48 hours associated with vomiting and photophobia, similar to attacks in childhood. One week later he noticed double vision and one week after that unsteadiness of gait; during these three weeks he had further attacks of headache with intervening continuous occipital headache.

EXAMINATION He was alert but slow in giving his history. There was a left partial sixth nerve palsy, bilateral horizontal first degree nystagmus more marked to the left, and left-sided nerve deafness. There was slight weakness of the left wrist extensors and hand muscles, and hypotonia, finger-nose ataxia, intention tremor, rebound and dysdiadochokinesia in the left limbs, and the left plantar response was extensor. Gait was severely ataxic. In particular, there was neither fever nor clubbing, no abnormality in the cardiovascular and respiratory systems, and no palpable spleen. Blood pressure was $150 / 70 \mathrm{~mm} \mathrm{Hg}$. There was no scalp tenderness, and the middle ears were completely normal.

A clinical diagnosis was made of a left cerebellar or cerebello-pontine angle lesion, the deafnessfavouring the latter. Acoustic neuroma, metastasis, meningioma, and haemangioblastoma were considered.

INVESTIGATIONS Urine contained no albumin, glucose, or pus cells, and no growth was obtained on culture. Haemoglobin was $16.3 \mathrm{~g} \%$, white cells $7,500 / \mathrm{cu}$. mm and ESR $46 \mathrm{~mm} / \mathrm{hr}$. Blood film was normal and WR negative. Sputum was purulent and no growth was obtained on culture. Chest and plain skull radiographs were normal. A ventriculogram showed the aqueduct to be displaced forwards and the fourth ventricle displaced to the right of midline and deformed by a left posterior fossa mass which was not typical of an acoustic neuroma; minimal supratentorial hydrocephalus was present.
Ventricular CSF was very pale yellow and slightly turbid with a clear supernatant, containing 210 red cells and 25 lymphocytes/cu. $\mathrm{mm}$ and protein $10 \mathrm{mg} / 100 \mathrm{ml}$. with no excess of globulin.

OPERATION (Mr. J. Garfield) On 31 January 1969 at a left suboccipital craniectomy in the sitting position with spontaneous respiration, an abscess with a wall of varying thickness and containing approximately $30 \mathrm{ml}$. pus was found occupying the left cerebellar hemisphere and extending into the tentorial hiatus; the wall was intimately related to the 7 th and 8 th cranial nerves. The abscess and its contents were removed completely and the dura closed Pneumococci were grown from the pus, and histology confirmed a chronic abscess.

High-dosage penicillin (16 Mega units daily) was givern postoperatively and the course was uneventful. By the 25 th postoperative day the deafness had resolved clinically, and only mild changes of presbycusis were found af otological examination before discharge on 6 March 1969

\section{DISCUSSION}

Cerebellar abscess usually presents with symptoms of raised intracranial pressure, but signs of cerebellar and cerebellar pathway disturbance may be slight. There is no mention of nerve deafness resulting from cerebellar tumour or abscess in standard neurological texts, and Griffith found no such case in his survey of 62 cases of cerebellar abscess (Griffith, 1969). A common cause of cerebellar abscess is middle ear infection, but when deafness is associated it is of conductive type. In our patient the finding of nerve deafness led to the diagnosis of a cerebello-pontine angle lesion; abscess was not considered because the middle ears were normal. The relationship of the abscess to the 8 th nerve as seen at operation would fully explain the otological findings, and the recovery of hearing after removal of the abscess.

Another unusual feature of this case is the metastatic origin of the solitary cerebellar abscess. In Griffith's series of 62 cerebellar abscesses, three cases were presumed metastatic; an incidence of $4.8 \%$ (Griffith, 1968). As often occurs, the site 
of origin of our patient's abscess remains obscure.

The penicillin-sensitive organism, slight CSF lymphocytosis, raised ESR, and normal peripheral blood white cell count are findings similar to those reported in other series of brain abscess (see Webster and Gurdjian, 1950, and Garfield, 1969).

SUMMARY

A case of solitary metastatic cerebellar abscess is reported with the very unusual feature of nerve deafness. The significance of this finding is discussed in relation to the difficulties in diagnosis and the anatomy of the lesion.
Our thanks are due to Mr. J. Garfield and to Dr. G. S. Graveson for permission to publish and for much helpful guidance and criticism. Reprints are available from Dr. C. Gardner-Thorpe, Wessex Neurological Centre, General Hospital, Southampton.

\section{REFERENCES}

Garfield, J. (1969). Management of supratentorial intracranial abscess; a review of 200 cases. Brit. med. J., 2, 7-11.

Griffith, H. (1968). Factors in the mortality of cerebellar abscess. (Abstr.). J. Neurol. Neurosurg. Psychiat., 31, 89.

(1969). Personal communication.

Webster, J. E., and Gurdjian, E. S. (1950). Collective review: surgical management of intracranial suppuration; methods in diagnosis and management, and report of 23 cases of civilian and 33 cases of military abscess. Int. Abstr. Surg., 90, 209-235.

\section{The June 1969 Issue}

\section{THE JUNE 1969 ISSUE CONTAINS THE FOLLOWING PAPERS}

Lactate dehydrogenase isozyme patterns in human skeletal muscle. I. Variation of isozyme pattern in the adult T. TAKASU and B. P. HUGHES

Lactate dehydrogenase isozyme patterns in human skeletal muscle. II. Changes of isozyme pattern in ontogeny T. TAKASU and B. P. HUGHES

Electrophysiological and histological observations on peripheral nerves in acrylamide poisoning in man PAMELA M. FULLERTON

The intramuscular nerve action potential L. GUTMANN

Relationships between and sensitivities of the galvanic skin reflex and two indices of peripheral vascoconstriction in man J. J. FUREDY and YVETTE GAGNON

See-saw nystagmus J. M. FEIN and R. D. B. WILliams

Electrophysiological localization of ulnar nerve lesions J. PAYAN
Medullary haemorrhage: a report of two cases F. L MASTAGLIA, B. EDIS, and B. A. KAKULAS

Oligodendrogliomas of the fourth ventıicle: report of two cases JAMES GREENWOOD, FRANK J. OTENASEK, and FRANK S. YELIN

Transient neurological disturbances in disseminated sclerosis: a case report M. HARRISON and J. I. MCGILL

Hypopituitarism with paranoid psychosis: a description of two cases S. A. W. DISSANAYAKE and D. K. LIEBERMAN

Transient embolic occlusion of the middle cerebral and internal arteries in cerebral apoplexy C. FIESCHI and L. BOZZAO

Pneumoencephalographic planimetry in neurological disease H. E. BOOKER, C. G. MATTHEWS, and W. R. WHITEHURST

Oligodendroglioma with extraneural metastases KURT JELLINGER, MARGARETE MINAUF, and MECHTHILD SALZERKUNTSCHIK

Book Reviews

Copies are still available and may be obtained from the PUBLISHING MANAGER, BRITISH MEDICAL ASSOCIATION, TAVISTOCK SQUARE, W.C.1, price $21 \mathrm{~s}$. 